\title{
Self-medication among pregnant women attending antenatal clinic at Tertiary Care Center of Nepal
}

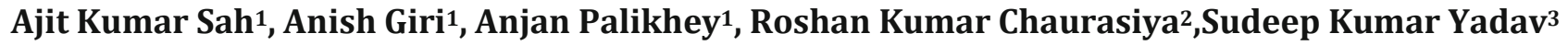

\author{
College of Medical Sciences \\ Bharatpur, Chitwan, Nepal
}

Lecturer, Department of Pharmacology, College of Medical Sciences, Bharatpur, Chitwan, Nepal

Lecturer, Department of Pharmacology, Chitwan Medical Sciences, Bharatpur, Chitwan, Nepal

Associate Professor, Department of Anatomy, Janaki Medical College, Janakpurdham, Nepal

\begin{abstract}
Background and Objectives: Self-medication can cause significant challenges for the individuals and community, especially in women during pregnancy. The aim of this study was to evaluate the prevalence of self-medication among the pregnant women attending antenatal clinic in a tertiary care center of Nepal.
\end{abstract}

Material and Methods: In this cross-sectional study, a total of 225 pregnant women were evaluated for the prevalence of self-medication during pregnancy. Descriptive statistics and chi-square tests were used for statistical analysis of data.

Results: The results showed that the prevalence of self-medication, in pregnant women was $41.3 \%$. The leading illness/ symptoms which led to self-medication among pregnant women attending clinic were to relieve headaches 29 (31.2\%), cough 21 (22.6\%), vomiting 13 (14\%), treat fever $11(11.8 \%)$, urinary tract infections 11 (11.8\%) and drugs commonly reported for self-medication were paracetamol (30.10\%), cough remedies (19.30\%), antiemetics (16.13\%), analgesisc (10.75\%).

Conclusion: Prevalence of self-medication among pregnant women is high in Nepal. This is a threat to the safety of the developing foetus and the pregnant woman. Therefore, it seems necessary to provide public trainings for all women of reproductive age and train them about the dangers and side effects of self-medication.

Key words: Drug Safety, Fetus, Pregnancy, Self-medication

\section{INTRODUCTION}

Self-medication can be defined as the use of drugs to treat self-diagnosed disorders or symptoms, or the intermittent or continued use of a prescribed drug for chronic or recurrent disease or symptoms [1]. Careful consideration of the benefit to the mother and the risk to the fetus is required while drugs are used during pregnancy. As it is a challenging medical condition for the clinicians in the treatment and the selection of drugs for disease management because of various pharmacokinetic $[2,3]$ and physiological changes $[4,5]$ in woman's body. Those changes often present various complications during pregnancy [7]. Selfmedication carries serious risk of drug interactions, poly-pharmacy, misdiagnosis, excessive drug dosage use, prolonged drug 
use, incorrect drug choice, rare but severe adverse events, dependence or abuse and increased antimicrobial resistance [6 - 10].

The main reason for self-medication as reported from different countries include; the feeling that the condition/disease is mild thus not requiring doctor's consultation, previous good experience of treating similar illness, prompted by a pharmacist, feeling of independence to take care of him/herself and non-availability of doctors [11-13]. Advertisement by pharmaceutical companies or their agencies on drugs has also been established as a promoting factor for selfmedication [14].

Self-medication practice is common worldwide [15-20]. In Nepal, as in other countries, self-medication is a widespread practice, and the majority of medications consumer by the population is sold without medical prescriptions. Self-medication is a serious economic, social and health problem throughout the world, including Nepal [2123].

However, data on self-medication during pregnancy is scanty. There is a paucity of studies on self-medication among pregnant woman in Nepal. The present study was undertaken to identify the reasons for, and the patterns of, self-medication among medical students.

\section{MATERIAL AND METHODS}

The study was conducted at COMS TH with approval from the Institutional Ethics Committee. The study was conducted in the pharmacy of hospitals from 20 to 20, 2017. An institution based cross sectional study was conducted using a structured questionnaire based interview of pregnant women who were attending the ANC. The questionnaire was developed in Nepali then administered through face to face interviews after consent from the respondents. The questionnaire captured the information on the sociodemographic characteristics, self-medication and predictors for the practice. Pregnant women attending to antenatal clinic and willing to participate in the study were included in the study.

The collected date were entered into MS Excel and analyzed with SPSS version 16. Descriptive analysis was carried out on the study variables and prevalence rates were reported as percentages and 95\% confidence intervals. Chi-square was used to evaluate significant association among the study variables and $p$ values of $<0.05$ were considered statistically significant.

\section{RESULTS}

Two hundred and twenty five out of the 235 study participants participated in the study making the response rate of $95.7 \%$. The majority of the respondents, 93 (41.3\%), were in the age group of 24-29 years. Out of 225 respondents, 54 (24\%) were in first trimester, 99 (44\%) were in the second trimester and 72 (32\%) were in third trimester. Out of 225, 71(31.6\%), 93 (41.3\%) and 42 (18.7\%) were aged 18-23, 24-29 and 30-35 years respectively while only 19 $(8.4 \%)$ were $\geq 35$ years. Majority of participants were 143 (63.6\%) house wives while 82 (36.4\%) were employed.

Self-medication during pregnancy was practiced by 93 (41.3\%) pregnant women. Self-medication was 45 (48.4\%) during first trimester which significantly high with second trimester ( $\mathrm{p}<0.001), 9(9.6 \%)$ during second trimester and 39 (42\%) during third trimester. The most commonly drugs reported for self-medication were 
paracetamol, cough remedies, analgesics etc. Details of drug used for self-medication are shown in Fig 1.

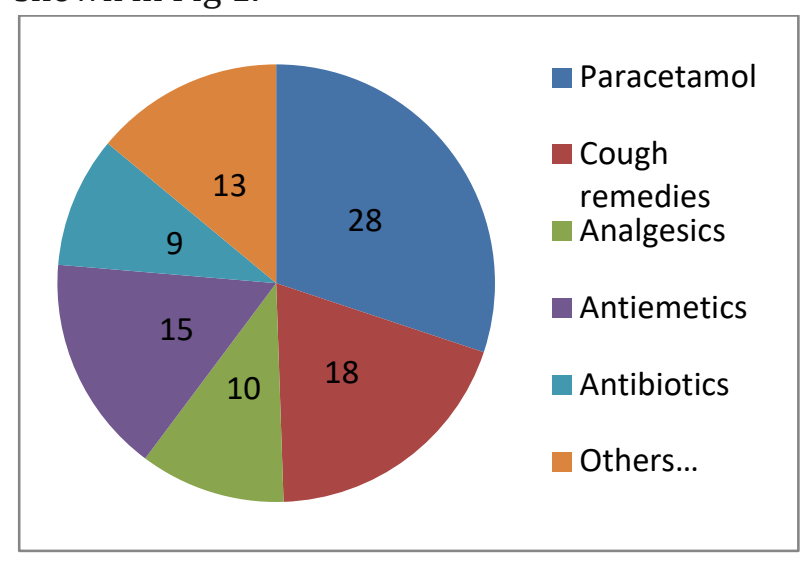

Figure 1.Drugs used for self-medication

The main reasons for self- medications were the disease not serious 43 (46.2\%), high cost to visit doctor 27 (29\%), time saving 18 (19.3\%) which is shown in Table 1.

Table 1: Main reason for self-medication

\begin{tabular}{|c|c|c|}
\hline $\begin{array}{c}\text { Reason for self- } \\
\text { medication }\end{array}$ & Frequency & $\begin{array}{c}\text { Percent } \\
\text { (\%) }\end{array}$ \\
\hline $\begin{array}{c}\text { Disease were not } \\
\text { serious }\end{array}$ & 43 & 46.2 \\
\hline High cost to visit doctor & 27 & 29 \\
\hline It is time saving & 18 & 19.3 \\
\hline $\begin{array}{c}\text { Drugs are easily } \\
\text { available }\end{array}$ & 5 & 5.4 \\
\hline
\end{tabular}

Table 2: Source of information for self-medication among pregnant women

\begin{tabular}{|c|c|c|}
\hline Source of information & $\begin{array}{c}\text { Frequency } \\
\text { (N) }\end{array}$ & $\begin{array}{c}\text { Percent } \\
\text { (\%) }\end{array}$ \\
\hline Friends & 26 & 28 \\
\hline Health professionals & 22 & 23.6 \\
\hline Neighour & 12 & 12.9 \\
\hline Social netework & 11 & 11.8 \\
\hline Others & 14 & 15.1 \\
\hline Husband & 8 & 8.6 \\
\hline
\end{tabular}

Self-medication was practiced mainly for relieve headaches $29(31.2 \%)$, treat fever 11 (11.8\%), cough 21 (22.6\%), vomiting 13 (14\%), urinary tract infections 11 (11.8\%) and others 8 (8.6\%). Among pregnant women who practice self-medication the most common source of information were their friend (28.2\%) which is shown in Table 2.

\section{DISCUSSION}

The present study was carried out in a tertiary care center in central Nepal to evaluate the prevalence and predictors of self-medication among pregnant women attending an antenatal clinic. We found that the prevalence of pregnant women using selfmedication was 41.3 percent. These results are comparable to those of other developing countries, especially Tanzania [24] $\{19\}$ and lower than Ethiopia (48\%) [25] and higher than Pakistan (37.9\%) [26], Iran 35.6\% [27] and Netherland (12.5\%) [28]. The possible explanations for the discrepancy may be due to differences in study methods, health care environments, and restriction policies of dispensing practices. Self-medication may cause significant difficulties for individuals and the community, especially in women during pregnancy, and it is important to be aware of the dangers and side effects of selfmedication by all women of reproductive age by public awareness.

The reasons why pregnant women practiced self-medication were ailments that were not serious, high doctor visit prices, time savings and quick access to prescription-free drugs from pharmacies or drug stores. Patients can prefer self-medication due to a lack of information about illnesses and symptoms. In developing countries, the lack of convenient access to government health care facilities makes it expensive in private hospitals. The ease of access to prescription-free drugs may be attributed to poor regulatory regulation of dispensing practices. The easy access to medicines without prescription might be due to inadequate regulatory enforcements of dispensing practices. This finding was similar 
to other studies conducted in Pakistan [26] and Indonesia [29].

Self-medication was greater in the first trimester and less frequent in the second trimester of pregnancy (Table 1). This result is a troubling hazard because drug exposure is likely to cause congenital malformations during this period given the high prevalence of congenital malformations recorded in our sample area [30]. In the first trimester, the greater self-medication activity can be due to the incidence of certain symptoms, discomforts and diseases such as nausea or vomiting, headache, dizziness and fevers in the first trimester than other trimesters during pregnancy [24].

Headache, cough and vomiting were the prominent problems/ symptoms requiring self-medication among pregnant women attending the clinic (Table 3). It is not shocking that headache is among the leading problems among pregnant women because it is a stressed condition that may lead to headache. Motion sickness is a common symptom experienced in pregnancy, especially in the first trimester, which correlates to the results of the current study that most pregnant women self-medicate when they have headache, nausea and vomiting [24].

Self-medication practice is one of the most common public health concerns during pregnancy. Unless necessary care is provided by responsible health professionals, it may lead to high risk, including maternal and neonatal mortality and morbidity [24, 25]. In this study, more than one third (41.3\%.) of the pregnant women had self-medicated with medicines. Drugs commonly used in selfmedication among pregnant women were paracetamol, cough remedies, analgesics, antiemetics and antibiotics. This indicated that some pregnant women were potentially at higher risk. For instance paracetamol, the commonest non-steroidal anti-inflammatory drugs (NSAIDs), may also cause a risk of attention deficit hyperactivity in babies and reduced implantation sites at any time of pregnancy. Other NSAID like aspirin and ibuprofen cause premature closure of ductusarteriosus during the third trimester, miscarriage, cardiac malformation, fetal renal impairment, pulmonary hypertension, and delayed onset of labor and prolongation of bleeding time in mother [25].

\section{CONCLUSION}

The study conducted with the objective of A considerable proportion of pregnant women attending antenatal care practiced selfmedication.There is lack of attention among policy makers and program designers on addressing the risk of self-medication. There were no guidelines and recommendations on self-medication during pregnancy. There was also weak regulation enforcement on medicine retail outlets as they were good sources of medicines for self-medication. In addition, the pregnant women have limited awareness on self-medication, and they believe the advices of their friends and families.

Therefore, it is important to aware the pregnant women with risks of selfmedication and train health care providers on how to help pregnant women stay safe from self-medication. Moreover, concerted efforts need to be exerted to strengthen regulatory enforcements and routinely screen pregnant women. We recommend further research to assess the consequences of self-medication practice on pregnancy outcomes and community-based studies to identify factors

\section{ACKNOWLEDGEMENTS}


We would like to appreciate the management of College of Medical sciences, Chitwan, Nepal for their support.

\section{REFERENCES}

1. Kunin, C.M. Problems of antibiotic usage: Definitions, causes and proposed solutions. Ann. Intern. Med. 1978; 89: 802-5.

2. Blackburn S. Pharmacokinetic changes in the pregnant woman. J Perinat Neonatal Nurs. 2012; 26:13-14.

3. Dawes M, Chowienczyk PJ. Pharmacokinetics in pregnancy. Best Pract Res ClinObstetGynaecol. 2001;15:819-26.

4. DiPiro JT, Talbert RL, Yee G, Matzke GR, Wells BG, Posey LM, et al. Pharmacotherapy: a pathophysiologic approach. 7th ed. New York: McGraw Hill Companies; 2005.

5. McPhee SJ, Papadakis MA, Rabow MW. Current medical diagnosis \& treatment 2012. 45th ed. New York: McGraw-Hill Medical; 2006.

6. Hughes CM, McElnay JC, Fleming GF. Benefits and risks of self - medication. Drug Safety. 2001;24(14):1027-37.

7. Awad A, Eltayeb I, Matowe L, Thalib L. Selfmedication with antibiotics and antimalarials in the community of Khartoum state, Sudan. J Pharm Pharm Sci. 2005;8(2):326-31.

8. Hardon A, Van der Geest S. Hazards of selfmedication. World Health Forum: 1987. 1987:469-71.

9. Pfeiffer K, Some F, Müller O, Sie A, Kouyate B, Haefeli $W$ et al. Clinical diagnosis of malaria and the risk of chloroquine self-medication in rural health centres in Burkina Faso. Tropical Med Int Health. 2008;13(3):418-26.

10. Organization WH: Guidelines for the regulatory assessment of medicinal products for use in self-medication. 2000.

11. Garofalo L, Di Giuseppe G, Angelillo IF. Selfmedication practices among parents in Italy. Biomed Res Int. 2015;2015

12. Suleman S, Ketsela A, Mekonnen Z. Assessment of self-medication practices in Assendabo town, Jimma zone, southwestern Ethiopia. Res SocAdm Pharm. 2009;5(1):76-81.

13. Afolabi A. Factors influencing the pattern of self-medication in an adult Nigerian population. Annals of African medicine. 2009;7(3):120-7.
14. TYK BIDUKI. The effects of advertisement on self-medication: case study of EjuraSekyedumase municipality. Department of Economics, Kwame Nkrumah university of Sci Technol. 2013.

15. Goossens, H.; Ferech, M.; Vander Stichele, R.; Elseviers, M. Outpatient antibiotic use in Europe and association with resistance: A cross-national database study. Lancet 2005, 365, 579-87.

16. World Health Organization. Guidelines for the Regulatory Assessment of Medicinal Products for Use in Self-Medication; WHODEDM/QSM/001; WHO: Geneva, Switzerland, 2000.

17. Skliros E.; Merkouris, P.; Papazafiropoulou A.; Gikas A.; Matzouranis G.; Papafragos, C. et al. Self-medication with antibiotics in rural population in Greece: A cross-sectional multicenter study. BMC Fam. Pract. 2010, 11, doi:10.1186/1471-2296-11-58.

18. Ebert, S.C. Factors contributing to excessive antimicrobial prescribing. Pharmacotherapy 2007, 27, 126-130.

19. Friedman, C.R.; Whitney, C.G. It's time for a change in practice: Reducing antibiotic use can alter antibiotic resistance. J. Infect. Dis. 2008, 197, 1082-1083.

20. Vila, J.; Pal, T. Update on antibacterial resistance in low-income countries: Factors favouring the emergence of resistance. Open Infect. Dis. J. 2010, 4, 38-54.

21. POUDEL SABITA, ARYAL BIJAY Exploration of self-medication practice in Pokhara valley of Nepal. BMC Public Health (2020) 20:714

22. Parajuli S., Mishra A., Bhattarai P., Karki S.,Pandit R., \&Dahal P. (2019). Self-Medication Practices in Surrounding Communities of Birat Medical College and Teaching Hospital of Eastern Nepal. Journal of College of Medical Sciences-Nepal, 15(1), 45-52.

23. PR Shankar, P Partha and N Shenoy. Selfmedication and non-doctor prescription practices in Pokhara valley, Western Nepal: a questionnaire-based study. BMC Family Practice 2002, 3:1-7.

24. Karol J. Marwa, Agnes Njalika, DeodatusR., Deogratias K and Erasmus K. Self-medication among pregnant women attending antenatal clinic at Makongoro health centre in Mwanza, Tanzania: a challenge to health systems BMC Pregnancy and Childbirth (2018) 18:16 
25. Kidanemariam G/Michael Beyene and Solomon WorkuBeza. Self-medication practice and associated factors among pregnant women in Addis Ababa, Ethiopia Tropical Medicine and Health (2018) 46:10

26. Bohio R, Brohi Z, Bohio F. Utilization of over the counter medication among pregnant women; a cross-sectional study conducted at Isra University Hospital, Hyderabad. The Journal of the Pakistan Medical Association. 2016; 66(1):68-71.

27. Baghianimoghadam M. Attitude and practice of pregnant women regarding self-medication in Yazd, Iran. Archives of Iranian Medicine. 2013; 16(10):580.

28. Gwenny MPJ Verstappen, Elise J Smolders, Janna M Munster, Jan G Aarnoudse2 and EelkoHak. Prevalence and predictors of overthe-counter medication use among pregnant women: a cross-sectional study in the Netherlands. BMC Public Health 2013, 13:185

29. RizkaNoviaAtmadani, Owen

Nkoka, SendiLiaYunita \& Yi-Hua Chen. Selfmedication and knowledge among pregnant women attending primary healthcare services in Malang, Indonesia: a cross-sectional study. BMC Pregnancy and Childbirth (2020) 20:42

30. Bérard A, Ramos E, Rey E, Blais L, St-André M, Oraichi D. First trimester exposure to paroxetine and risk of cardiac malformations in infants: the importance of dosage. Birth Defects Research Part B: Developmental and ReprodToxicol. 2007;80(1):18-27.

\section{Correspondence to:}

Ajit Kumar Sah

Lecturer, Department of Pharmacology

College of medical Sciences

Bhartpur, Chitwan, Nepal 